\title{
Panobinostat/Carfilzomib Regimen
}

National Cancer Institute

\section{Source}

National Cancer Institute. Panobinostat/Carfilzomib Regimen. NCI Thesaurus. Code C136276.

A chemotherapy regimen consisting of panobinostat and carfilzomib that is used for the treatment of plasma cell myeloma. 